\title{
Chapter 21 \\ Urban Sensing with Spaceborne \\ Interferometric Synthetic Aperture \\ Radar
}

\author{
Hongyu Liang, Wenbin Xu, Xiaoli Ding, Lei Zhang, and Songbo Wu
}

\begin{abstract}
Synthetic aperture radar (SAR) and interferometric SAR (InSAR) are state-of-the-art radar remote sensing technologies and are very useful for urban remote sensing. The technologies have some very special characteristics compared to optical remote sensing and are especially advantageous in cloudy regions due to the ability of the microwave radar signals used by the current SAR sensors to penetrate clouds. This chapter introduces the basic concepts of SAR, differential InSAR, and multi-temporal InSAR, and their typical applications in urban remote sensing. Examples of applying the various InSAR techniques in generating DEMs and monitoring ground and infrastructure deformation are given. The capabilities and limitations of InSAR techniques in urban remote sensing are briefly discussed.
\end{abstract}

\subsection{Synthetic Aperture Radar}

A radar (RAdio Detection and Ranging) system typically sends out electromagnetic pulses and receives the pulses scattered back by objects. By precisely determining the time delay and Doppler frequency shift between the emitted and received pulses, a radar system can measure the distance to, and the moving velocity of, an object with respect to the radar. Synthetic-aperture radar (SAR) is a commonly used radar remote sensing technique that achieves finer spatial resolution imaging (i.e., up to meter level or better), in comparison with the real aperture radar, by taking advantage of the movement of the radar antenna along a particular trajectory to mathematically create a virtual radar antenna that has a much larger size than that of the physical antenna. The radar system is usually mounted on an aircraft or a satellite with a side-looking imaging geometry (Fig. 21.1). Most spaceborne SAR antennas are 10$15 \mathrm{~m}$ long and result in a ground spatial resolution of $1-20 \mathrm{~m}$ by using the SAR principle. Since the first spaceborne SAR satellite was launched in 1978 by the U.S. National Aeronautics and Space Administration (NASA), many SAR satellites have

H. Liang $\cdot$ W. Xu $\cdot$ X. Ding $(\bowtie) \cdot$ L. Zhang $\cdot$ S. Wu

Department of Land Surveying and Geo-Informatics, The Hong Kong Polytechnic University,

Hong Kong, China

e-mail: xl.ding@polyu.edu.hk 


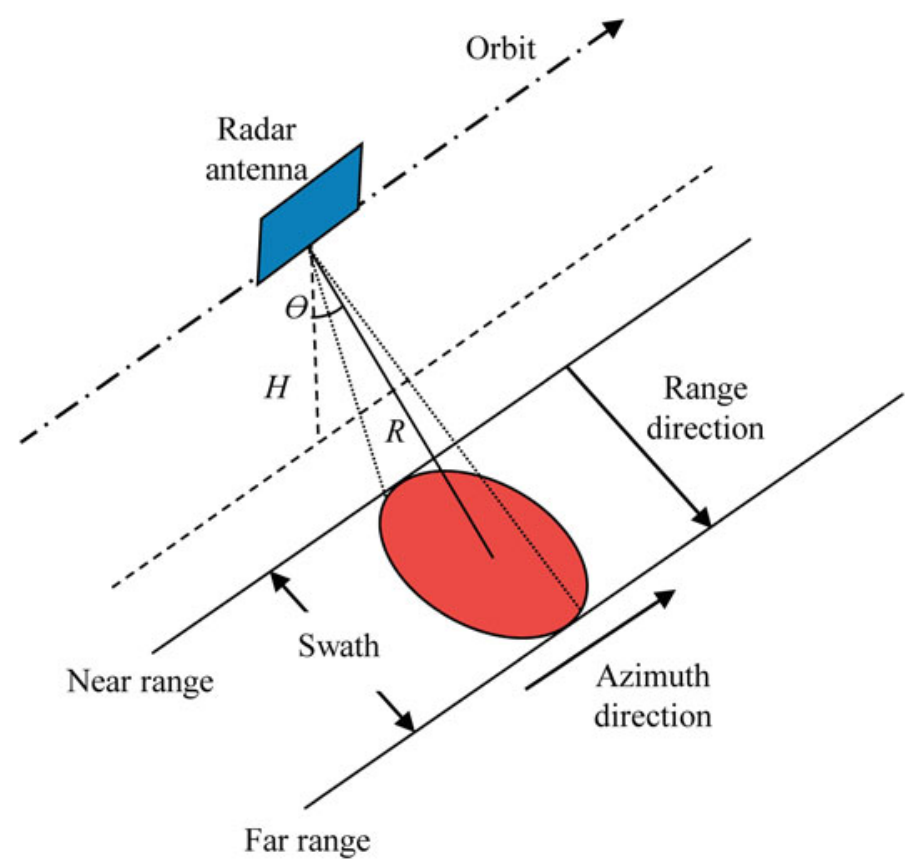

Fig. 21.1 Typical SAR imaging geometry. The antenna receives the backscattered signal from the illuminated area. The moving direction of the satellite is called the azimuth direction of the image, while the direction of radar illumination is referred to as the range direction of the image. $H$ and $R$ are the height of the satellite and the slant range between the satellite and a ground resolution cell, respectively. $\theta$ represents the look angle

been developed (Table 21.1). Over ten SAR satellites are currently in operation or to be launched in the near future.

A SAR system obtains information on both the intensity and the phase of the returned signal from each ground resolution cell, referred to as pixel. The intensity depends primarily on the roughness and dielectric property of the scattering surface while the phase is determined by the time delay between signal transmission and reception. The signal in a pixel can be represented by

$$
y_{1}=a_{1}+b_{1} i=A_{1} \cdot \mathrm{e}^{i \varnothing_{1}}
$$

where $a_{1}$ and $b_{1}$ are the real and imaginary parts of the complex value; and $A_{1}$ and $\varnothing_{1}$ represent the amplitude and phase of the signal. 
Table 21.1 SAR satellites launched to date

\begin{tabular}{|c|c|c|c|}
\hline Satellite & Operator & Band/wavelength $(\mathrm{cm})$ & Operational period \\
\hline Seasat & $\begin{array}{l}\text { U.S. National } \\
\text { Aeronautics and Space } \\
\text { Administration (NASA) }\end{array}$ & $\mathrm{L} / 23.5$ & 1978 \\
\hline ERS-1 & $\begin{array}{l}\text { European Space Agency } \\
\text { (ESA) }\end{array}$ & $\mathrm{C} / 5.66$ & $1991-2000$ \\
\hline JERS-1 & $\begin{array}{l}\text { Japan Aerospace } \\
\text { Exploration Agency } \\
\text { (JAXA) }\end{array}$ & $\mathrm{L} / 23.5$ & $1992-1998$ \\
\hline ERS-2 & $\begin{array}{l}\text { European Space Agency } \\
\text { (ESA) }\end{array}$ & $\mathrm{C} / 5.66$ & 1995-2011 \\
\hline Radarsat-1 & $\begin{array}{l}\text { Canadian Space Agency } \\
\text { (CSA) }\end{array}$ & $\mathrm{C} / 5.66$ & 1995-2013 \\
\hline Envisat & $\begin{array}{l}\text { European Space Agency } \\
\text { (ESA) }\end{array}$ & $\mathrm{C} / 5.66$ & 2002-2012 \\
\hline ALOS & $\begin{array}{l}\text { Japan Aerospace } \\
\text { Exploration Agency } \\
\text { (JAXA) }\end{array}$ & $\mathrm{L} / 23.5$ & 2006-2011 \\
\hline Radarsat-2 & $\begin{array}{l}\text { Canadian Space Agency } \\
\text { (CSA) }\end{array}$ & $\mathrm{C} / 5.66$ & $2007-$ \\
\hline TerraSAR-X & $\begin{array}{l}\text { German Aerospace } \\
\text { Center (DLR) }\end{array}$ & $\mathrm{X} / 3.1$ & $2007-$ \\
\hline $\begin{array}{l}\text { COSMO-SkyMed } \\
\text { constellation }\end{array}$ & $\begin{array}{l}\text { Italian Space Agency } \\
\text { (ASI) }\end{array}$ & $\mathrm{X} / 3.1$ & $2007-$ \\
\hline TanDEM-X & $\begin{array}{l}\text { German Aerospace } \\
\text { Center (DLR) }\end{array}$ & $\mathrm{X} / 3.1$ & 2010 \\
\hline Sentinel-1A & $\begin{array}{l}\text { European Space Agency } \\
\text { (ESA) }\end{array}$ & $\mathrm{C} / 5.66$ & $2014-$ \\
\hline ALOS-2 & $\begin{array}{l}\text { Japan Aerospace } \\
\text { Exploration Agency } \\
\text { (JAXA) }\end{array}$ & $\mathrm{L} / 23.5$ & $2014-$ \\
\hline Sentinel-1B & $\begin{array}{l}\text { European Space Agency } \\
\text { (ESA) }\end{array}$ & $\mathrm{C} / 5.66$ & $2016-$ \\
\hline Gaofen-3 & $\begin{array}{l}\text { China National Space } \\
\text { Administration (CNSA) }\end{array}$ & $\mathrm{C} / 5.66$ & $2016-$ \\
\hline PAZ & Hisdesat & $\mathrm{X} / 3.1$ & $2018-$ \\
\hline
\end{tabular}

\subsection{Interferometric Synthetic Aperture Radar}

Basic interferometric synthetic aperture radar (InSAR) involves a pair of focused complex SAR images of the same ground area and acquired with the same or similar imaging geometries, often referred to as single look complex (SLC) images. InSAR extracts very useful information from the interferometric combination of the two SAR 
images separated in space and time. The spatial separation between the two images is termed the spatial baseline, while the temporal separation forms the temporal baseline when the SAR images are acquired from repeat-pass orbits using the same antenna.

After alignment and resampling of the two SAR images into the same geometry, a complex interferogram is generated by coherent cross-multiplication of the two SAR images,

$$
v=y_{1} \cdot y_{2}^{*}=A_{1} A_{2} \cdot \mathrm{e}^{\left(i \varnothing_{1}-\varnothing_{2}\right)}
$$

where $v$ represents the signal in a pixel of the interferogram. The phase component of the signal $\varnothing_{1}-\varnothing_{2}$ gives the phase difference between the SAR images. For a single SAR image, although the phase values appear quite random in space, the difference between the two images offers very useful information (see Fig. 21.2). The phase difference $\varnothing_{1}-\varnothing_{2}$ can be decomposed into two components,

$$
\varnothing=\varnothing_{1}-\varnothing_{2}=-\frac{4 \pi}{\lambda}\left(R_{1}-R_{2}\right)+\left(\psi_{\text {scat }, 1}-\psi_{\text {scat }, 2}\right)
$$

where $\lambda$ is the wavelength of the radar signal, $R_{1}$ and $R_{2}$ are the slant ranges from the antenna positions to the ground target for two SAR acquisitions, and $\psi_{\text {scat, } 1}$ and $\psi_{\text {scat, } 2}$ are related to the interactions between the radar signal and the ground scatterers.
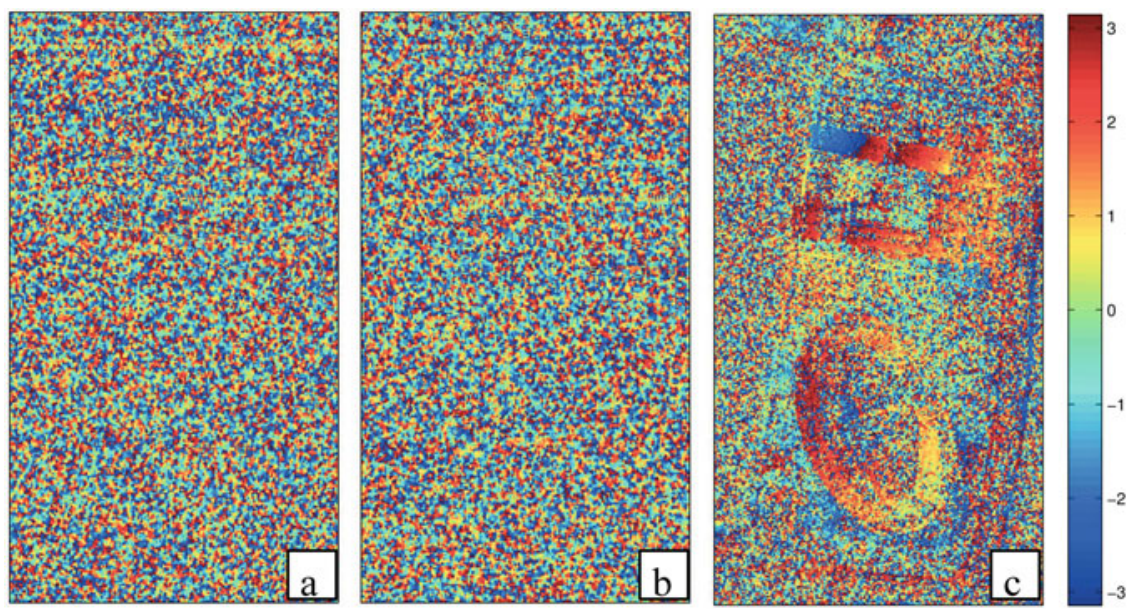

Fig. 21.2 a Phase image of a TerraSAR SLC image acquired on July 22, 2011, over East Asian Games Dome, Macau. b Phase image of a TerraSAR SLC image acquired on October 7, 2011, over the same area. $\mathbf{c}$ Interferometric phase generated by differencing image a and $b$; the interferometric phase values show some regular patterns which contain information about the ground surface topography, deformation, etc. The units are in $\pi$. The phase values of $a, b$, and $c$ are modulo $2 \pi$, ranging from $-\pi$ to $\pi$ 
Although the interactions are unpredictable in real cases, the scattering will remain coherent if the spatial and temporal separations between the SAR acquisitions are small. As a consequence, the phase difference is mainly dependent on the range difference $R_{1}-R_{2}$ as the interaction phase contributions mostly cancel out.

From a geometry perspective, the interferometric phase can also be defined as:

$$
\varnothing=\varnothing_{\text {flat }}+\varnothing_{\text {topo }}+\varnothing_{\text {defo }}+\varnothing_{\text {atm }}+\varnothing_{\text {orb }}+\varnothing_{\text {noise }}
$$

where $\varnothing_{\text {flat }}$ is the flattening phase and is due to the slant range variation with the elevation of the reference surface; $\varnothing_{\text {topo }}$ is the phase component resulted from the topography; $\varnothing_{\text {defo }}$ is the phase caused by ground surface displacement; $\varnothing_{\text {atm }}$ is due to the phase propagation delay when the radar signal travels through the atmosphere; $\varnothing_{\text {orb }}$ is related to the phase induced by inaccurate orbit data, and $\varnothing_{\text {noise }}$ is the phase caused by the noise. Since the wavelength of the radar signal is normally in the $\mathrm{cm}$ range (see Table 21.1), the phase contributions can be measured to an accuracy of $\mathrm{mm}$, i.e., a fraction of the wavelength.

In early applications, radar interferometry was primarily used to map land surface topography, with a comparable accuracy (i.e., meter level) to photogrammetric methods and capability of working under all weather conditions. It was then soon demonstrated that repeat-pass interferometry could measure relative surface displacement, yielding a $\mathrm{cm}$ to $\mathrm{mm}$ accuracy. InSAR has been used extensively to retrieve ground surface deformation that is related to natural or anthropogenic activities, such as earthquakes (e.g., Fialko 2004), volcano eruption (e.g., Lu and Dzurisin 2014), glacier change (e.g., Goldstein et al. 1993), landslides (e.g., Sun et al. 2015), and land subsidence due to extraction of water or other resources (e.g., Qu et al. 2015). We will briefly introduce below how to use SAR interferometry to produce a ground surface deformation map.

The method of using two SAR images to perform interferometry for deformation mapping is called differential InSAR (DInSAR) (Massonnet and Feigl 1998). Disregarding atmospheric propagation delay and satellite orbit errors, before obtaining a deformation image, the flattening and topographic phase contributions need to be removed from the interferogram,

$$
\begin{aligned}
& \varnothing_{\text {flat }}=-\frac{4 \pi}{\lambda} \frac{B_{\perp} s}{R \tan \theta} \\
& \varnothing_{\text {topo }}=-\frac{4 \pi}{\lambda} \frac{B_{\perp} h}{R \sin \theta}
\end{aligned}
$$

where $B_{\perp}$ is the perpendicular baseline; $R$ is the slant range from the antenna to the ground point; $\theta$ is the incidence angle of the radar signal; and $\mathrm{s}$ and $\mathrm{h}$ represents the differences of slant range and elevation with respect to a reference point, respectively. These parameters can be obtained from a SAR system configuration. The operation of removing the flattening phase is called interferogram flattening and the result is a flattened interferogram (see Fig. $21.3 \mathrm{~b}, \mathrm{c}$ ). The removal of the topographic 

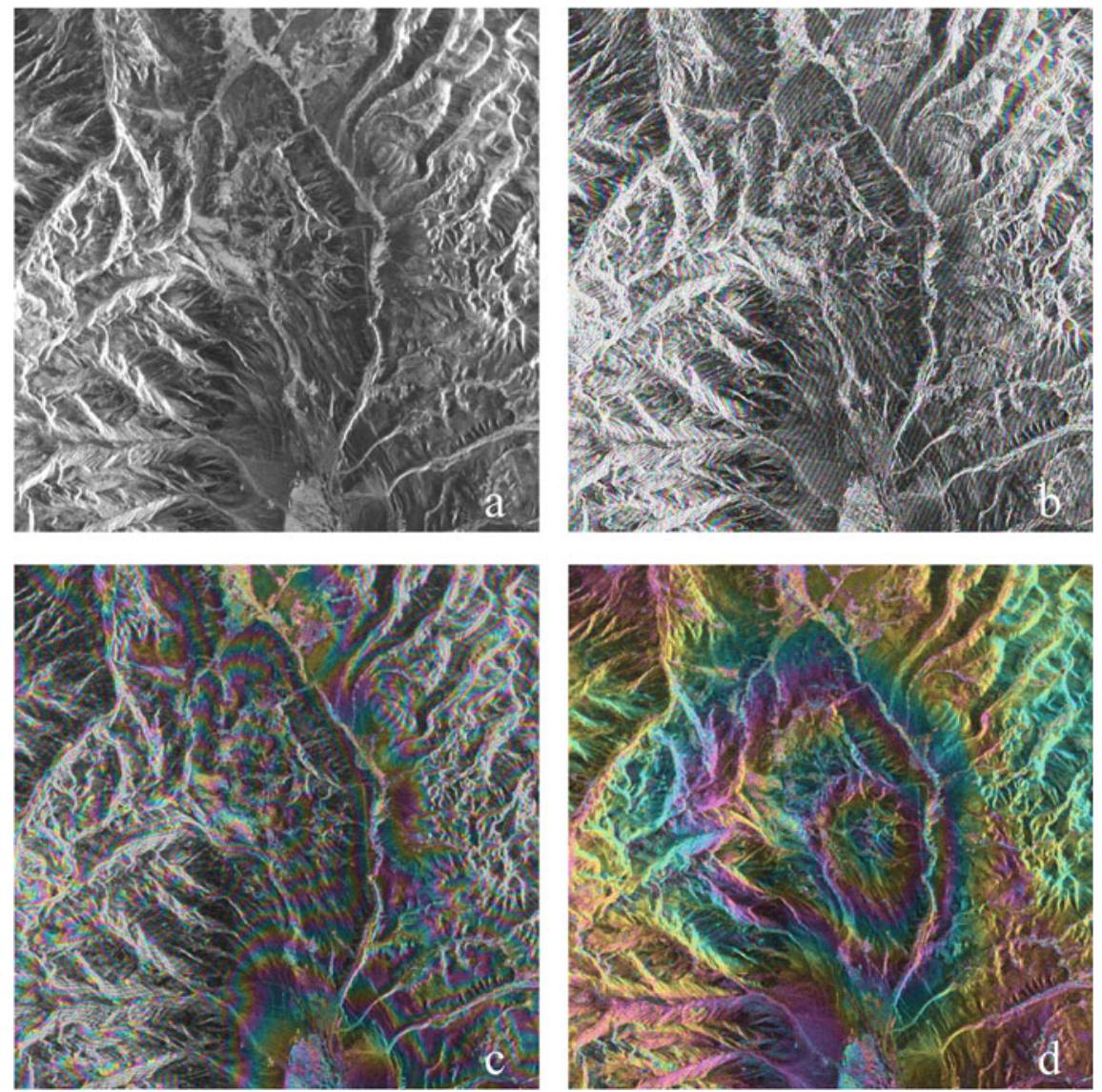

Fig. 21.3 a Amplitude image of a PALSAR image acquired on July 3, 2008, over Dangxiong, China. b Original interferogram formed by differencing two PALSAR images acquired from July 3, 2008, and February 18, 2009, respectively. The fringes with $2 \pi$ phase-cycle reflect the contributions of the reference surface, topography, deformation, etc. c Interferogram after flattening. d Interferogram after flattening and removal of topographic phase. The resulting fringes mainly contain surface deformation produced by the Mw 6.3 earthquake that occurred on October 6, 2008

phase can be achieved by deploying an external digital elevation model (DEM) and the InSAR imaging geometry to simulate a synthetic interferogram and then subtracting the phase contribution from the flattened interferogram (Massonnet and Feigl 1998). Currently, there are several global DEM datasets generated based on this technique, including results from the Shuttle Radar Topographic Mission (SRTM; Farr et al. 2007) and ALOS Global Digital Surface Model "ALOS World 3D-30m" (AW3D30m; Tadono et al. 2016). Alternatively, the synthetic interferogram can be directly formed from other SAR acquisitions of the same area with short temporal separation and then can be scaled to the spatial baseline of the original interferogram. The combination of the original interferogram with a third or fourth SAR acquisition 
is called three-pass or four-pass InSAR (Zebker and Rosen 1994), as the approaches use additional SAR images to produce the DEM interferogram that is assumed to solely contain the topographic contribution.

Subtracting flattening and topographic phases from the original interferogram results in a differential interferogram (see Fig. 21.3d). Since atmospheric propagation delay and other systematic errors are neglected at this point, the resulting phase observations can be regarded as the sum of two contributions: (1) the relative ground displacement that occurs during the time interval between the SAR acquisitions, and (2) phase noise due to ground scattering characteristics that are related to the variation of spatial and temporal baselines. The phase noise propagates into the derived displacement map and degrades the quality of the results. To mitigate the noise effect, a low-pass filter can be applied to improve the signal-to-noise ratio (SNR) of the phase measurement, but at the cost of possible image resolution reduction (Goldstein and Werner 1998).

The filtered interferogram contains information mainly on the ground motion. However, it is impossible to directly convert the filtered differential interferogram into a displacement map as the interferometric phase values are modulo $2 \pi$, ranging from $-\pi$ to $\pi$. The wrapped phase values require adding the correct multiple of $2 \pi$ to recover the absolute phase values. This procedure is referred to as phase unwrapping. Many different phase unwrapping methods have been proposed, such as the residue cut (Goldstein et al. 1988), least squares (Ghiglia and Romero 1994; Pritt and Shipman 1994), and minimal cost flow methods (Costantini 1998). Each of the methods has its own pros and cons and their performance depends on the noise level, the characteristics of terrain, and other conditions. Once the interferometric phases are unwrapped, the deformation map in the line-of-sight (LOS) direction can be obtained with respect to a reference point. As a summary, the workflow of DInSAR in extracting terrain deformation is shown in Fig. 21.4.

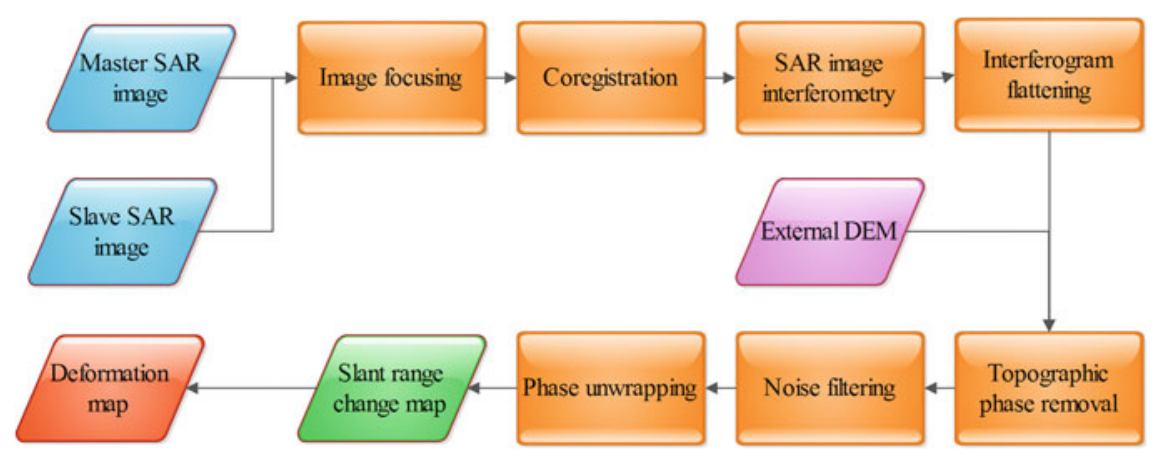

Fig. 21.4 Workflow of DInSAR processing for extracting a deformation map 


\subsection{Multi-temporal InSAR (MTInSAR)}

The effectiveness of the DInSAR approach is limited by several factors including errors in the external DEM that are used to remove the topographic phase, atmospheric propagation delays, phase ramps induced by orbit errors, spatial and temporal decorrelation, and phase unwrapping errors. The limitations have motivated the development of the multi-temporal InSAR (MTInSAR) technique that attempts to tackle the aforementioned problems by deploying a time series of SAR images covering the same area and focusing on scatterers with strong phase stabilities (i.e., persistent scatterers or PS).

After about 20 years of development, three categories of MTInSAR techniques are currently in existence. The first category of methods exploits single master (SM) interferograms and the methods include, for example, persistent scatterers InSAR (PSInSAR; e.g., Ferretti et al. 2001), the Stanford method for persistent scatterers (StaMPS; e.g., Hooper et al. 2004, 2007), and the spatiotemporal unwrapping network method (STUN; e.g., Kampes 2006; Kampes and Hanssen 2004). The second category of methods attempts to extract deformation information from scatterers with moderate phase stabilities (i.e., distributed scatterer or DS), where an interferogram stack is formed from multiple master (MM) interferograms. Examples include the small baseline subset (SBAS) technique (e.g., Berardino et al. 2002; Lanari et al. 2004), coherent point target (CPT; e.g., Mora et al. 2003), and temporally coherent point InSAR (TCPInSAR; e.g., Zhang et al. 2011a, b, 2014; Liang et al. 2019). In the third category, some newly developed techniques make use of all possible interferometric combinations to enhance the phase quality of DS, and then use the PS and the enhanced phase measurements of the DS to estimate the deformation information under the SM interferogram framework. The methods include SqueeSAR (e.g., Ferretti et al. 2011), component extraction and selection SAR (CAESAR; e.g., Fornaro et al. 2015), phase-decomposition-based InSAR (PDPSInSAR; e.g., Cao et al. 2016), and joint-scatterer InSAR (JSInSAR; e.g., Lv et al. 2014).

The innovations of the MTInSAR techniques are three-fold. First, high-quality coherent points form the foundation of MTInSAR. Methods for identifying such points have been developed based on different criteria, including the amplitude dispersion index (ADI; Ferretti et al. 2001), signal-to-clutter ratio (SCR; Adam et al. 2005), spatial phase stability (Hooper et al. 2004), coherence map (Jiang et al. 2015; Mora et al. 2003), and pixel offsets (Zhang et al. 2011a, b). Second, the various phase contributions need to be modeled according to the relationships between the signals and the phase observations. The contributions can be separated either based on InSAR observation itself (e.g., topographic error, orbital inaccuracy, height-related tropospheric delays; e.g., Zhang et al. 2014; Liang et al. 2019) or external data (e.g., atmospheric delays Jolivet et al. 2014). Finally, ground surface displacement history can be estimated from the function model. The estimation complexity depends on the existence of the phase ambiguities. On the one hand, the phase observations after the spatial unwrapping procedure can be easily solved by least squares. When it 
is challenging to carry out spatial phase unwrapping, temporal unwrapping can be performed. Typical methods include periodogram method (Ferretti et al. 2001), 3D phase unwrapping (Hooper et al. 2004), integer least squares (Kampes 2006), and least squares with outlier detection (Zhang et al. 2011a, b).

\subsection{Applications in Urban Areas}

It can be seen from the above discussion that the main applications of InSAR are in DEM generation and surface deformation mapping. It is often necessary to build 3D models of urban areas for purposes such as environmental modeling and urban planning. Monitoring ground and infrastructure deformation can provide essential information for better management of geohazards such as land subsidence, landslides, and sinkholes, and for ensuring the safety of urban infrastructures such as buildings, bridges, and road surfaces. We will discuss below applications of InSAR in DEM generation, land subsidence measurement, and infrastructure monitoring.

\subsubsection{Construction of Fine Resolution DEM}

Mapping urban topography is essential for a variety of scientific and practical applications, such as modeling urban heat island effects, urban landscape design, and urban planning. InSAR techniques can be used to generate DEM products of fine resolution in metropolitan areas. Especially data from the TanDEM-X mission has been used for generating accurate and detailed DEMs that cover the global area with an effective resolution of $6 \mathrm{~m}$ (Zhu et al. 2018). Based on the tandem SAR satellites TerraSAR-X and TanDEM-X, the mission performs single-pass SAR interferometry based on advanced algorithms for phase filtering and unwrapping. The singlepass bistatic interferogram has the advantage that the derived interferogram does not suffer from temporal decorrelation and atmospheric artefacts (Rossi and Gernhardt 2013), at the cost of spatial resolution due to phase filtering. Alternatively, by making use of repeat-pass acquisitions with full resolution, the MTInSAR technique can produce accurate urban DEMs with even finer spatial resolution (Perissin and Rocca 2006). Figure 21.5 presents the point cloud of a DEM product over Shenzhen, China. A total of 79 TerraSAR-X images spanning from May 2008 to May 2013 were used to generate the DEM product. The adopted methodology follows the MTInSAR processing framework (Wu et al. 2018), which has the characteristics of limiting atmospheric delays and mitigating decorrelation effects. It can be seen from Fig. 21.5 that the high-rise buildings (i.e., those higher than $100 \mathrm{~m}$ ) are clearly identified with regular spatial patterns. Figure 21.6 presents more detail of the DEM product, in which the point clouds match well with the 3D model of the buildings in Google Earth, demonstrating the effectiveness of MTInSAR for mapping urban topography. 


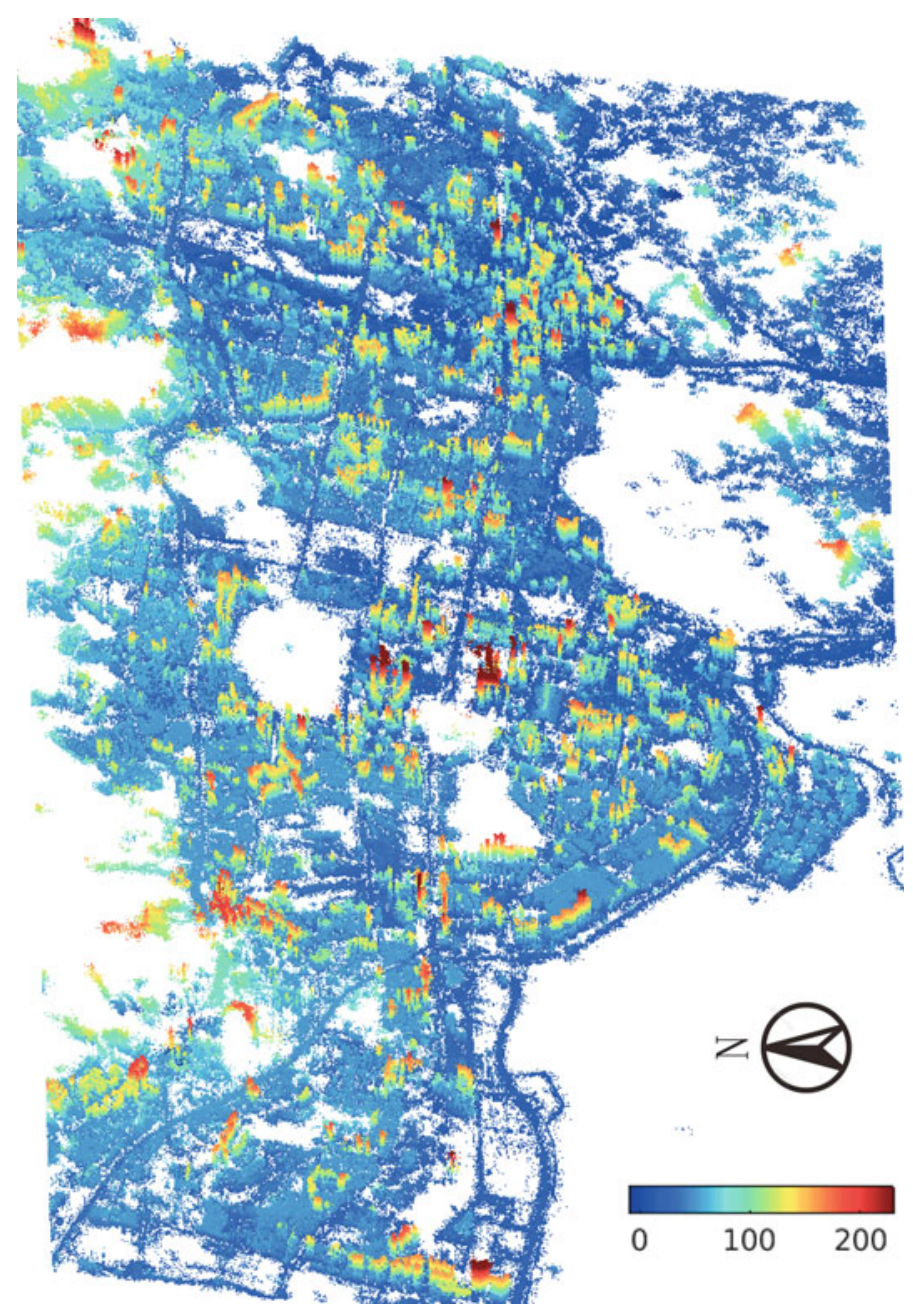

Fig. 21.5 Surface elevation model of part of Shenzhen from 79 TerraSAR-X images and MTInSAR processing

The InSAR technique is similar to stereophotogrammetry in that both use a pair of images to infer the target elevation. However, InSAR is also like the LiDAR technique as they both use range measurements. Compared to other topographic mapping techniques, the operation cost of InSAR is usually lower.

The weakness of InSAR in mapping urban topography includes specular reflection of signals, signal sidelobe, and geometric distortions of SAR images. Specular reflection of signals occurs when the ground surface is smooth, like a mirror. Little signal is backscattered in this case, leading to weak signal returns and loss of phase information. Sidelobe is caused by strong scatterers that contaminate the phase values of neighboring pixels. The geometric distortions, due to the oblique viewing geometry 

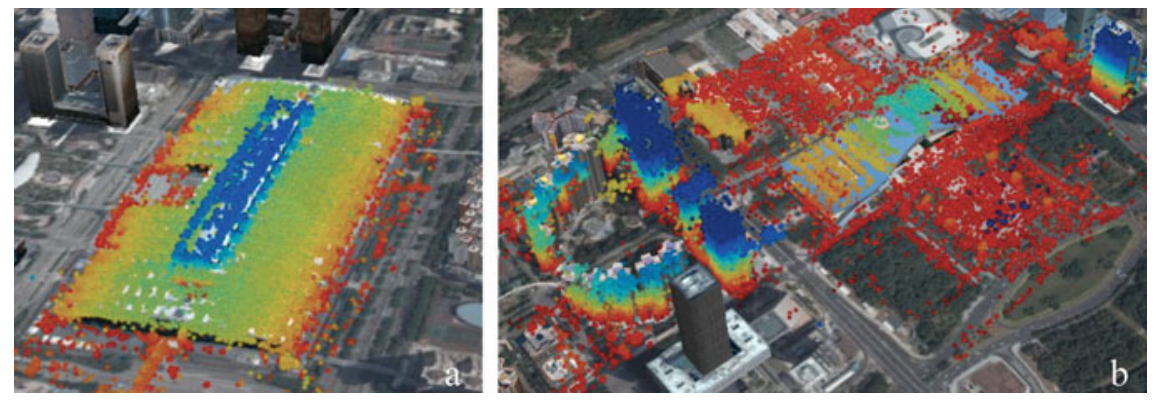

Fig. 21.6 Geocoded height maps of buildings over Shenzhen. a Shenzhen Convention \& Exhibition Center, b Shenzhen Citizen Center. The maps are superimposed on a Google Earth image (@ 2019 Google)

of SAR systems, have two main issues in urban environments, that is, shadowing and layover. Shadows occur when the radar signals are obscured by buildings or natural terrain, while layover is the result of superposition of multiple scatterers when terrain slope exceeds the radar incidence angle. With the development of advanced InSAR technologies, the effect of geometric distortions can be mitigated to a certain extent. SAR data from different viewing geometries (i.e., ascending and descending orbits) can be used complementarily to reduce the areas affected by shadows. For the layover problem, the elevation and deformation rate of the superimposed scatterers can be separately estimated by extending InSAR measurements into 4D (space-time) space. This operation is called differential SAR tomography (TomoSAR; (e.g., Lombardini 2005; Zhu and Bamler 2010).

\subsubsection{Subsidence Measurement}

The MTInSAR technique has enabled extraction of urban-area deformation with unprecedented spatial resolution. Due to the ample persistent scatterers in typical urban environments (e.g., buildings and other man-made structures), the temporal decorrelation effect is largely mitigated (Ferretti et al. 2001). The capability of InSAR in monitoring urban-area deformation has been extensively demonstrated in recent years.

Land subsidence caused by extracting groundwater is one of the emphases $(\mathrm{Qu}$ et al. 2015). Many areas in the world suffer from water shortages, especially in areas that are being rapidly urbanized. Figure 21.7 presents the area subsidence due to overuse of groundwater in Beijing. A total of 12 TerraSAR-X images were used to retrieve the subsidence field and its temporal evolution. The deformation results show that the largest deformation rate reaches $1.3 \mathrm{~cm} /$ year and the accumulative subsidence is $2.2 \mathrm{~cm}$ from 2010 to 2012. The InSAR derived deformation maps provide useful information on the amount and location of groundwater extraction. 


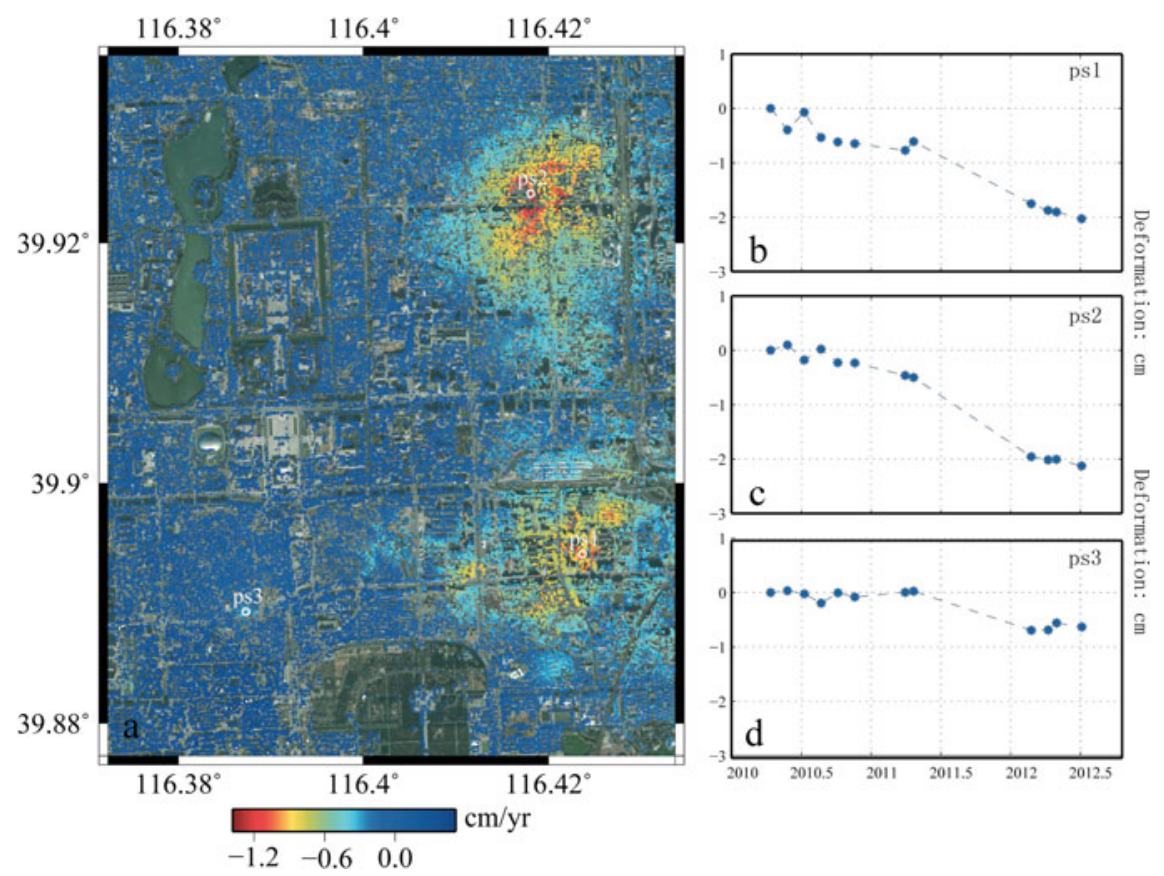

Fig. 21.7 a Deformation rate map over Beijing from 12 TerraSAR-X images and MTInSAR processing; b Deformation time series of ps1; c Deformation time series of ps2; $\mathbf{d}$ Deformation time series of ps3

Due to a shortage of useable land, many coastal cities reclaim land from the sea to support further urban development. A complex submarine geology can pose challenges for controlling the stability of reclaimed land (Shi et al. 2018). Figure 21.8 presents the rapid subsidence within only nine days over a man-made island. The InSAR technique has become a safe and efficient technique to extract terrain-motion information for analyzing geological stability and managing construction progress.

Subsidence caused by underground construction can be conveniently monitored by InSAR techniques (e.g., Serrano-Juan et al. 2017). Figure 21.9 shows the subsidence areas along subway lines revealed by processing 50 TerraSAR-X images from December 2013 to July 2016. Settlement due to the subway construction poses a potential threat to the surrounding areas. InSAR measurements can be used as input for analyzing the cause of subsidence.

Other land deformation such as that caused by sinkholes and landslides can also be monitored with InSAR. The feasibility of InSAR techniques for such applications depends on the rates of ground subsidence and surface features. 

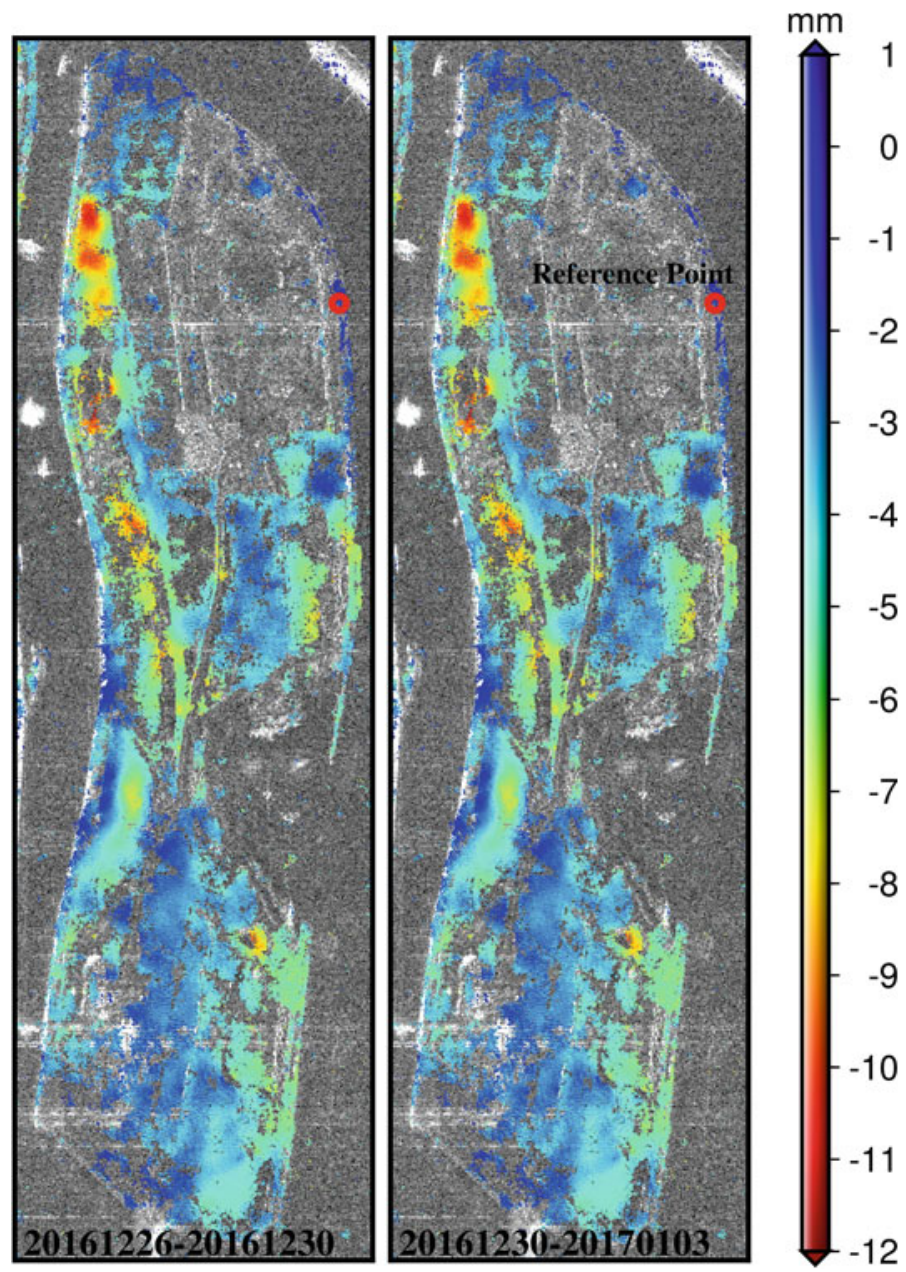

Fig. 21.8 Deformation map over a man-made island in Macau from three COSMO-SkyMed images and DInS AR processing

\subsubsection{Monitoring Stability of Infrastructures}

Urban infrastructures such as buildings and bridges are essential in supporting the daily lives of urban dwellers. It is important to check the stability of the infrastructures as any structural failure can lead to hazardous consequences. In-situ sensors such as accelerometers and traditional survey methods provide useful information on structural stabilities. It is however expensive to measure a large number of urban structures with these methods. InSAR, in particular MTInSAR, can be used to monitor both ground and structural deformation over a large area. It is therefore very efficient and provides very useful complementary information to the existing techniques (Ma and Lin 2016). 

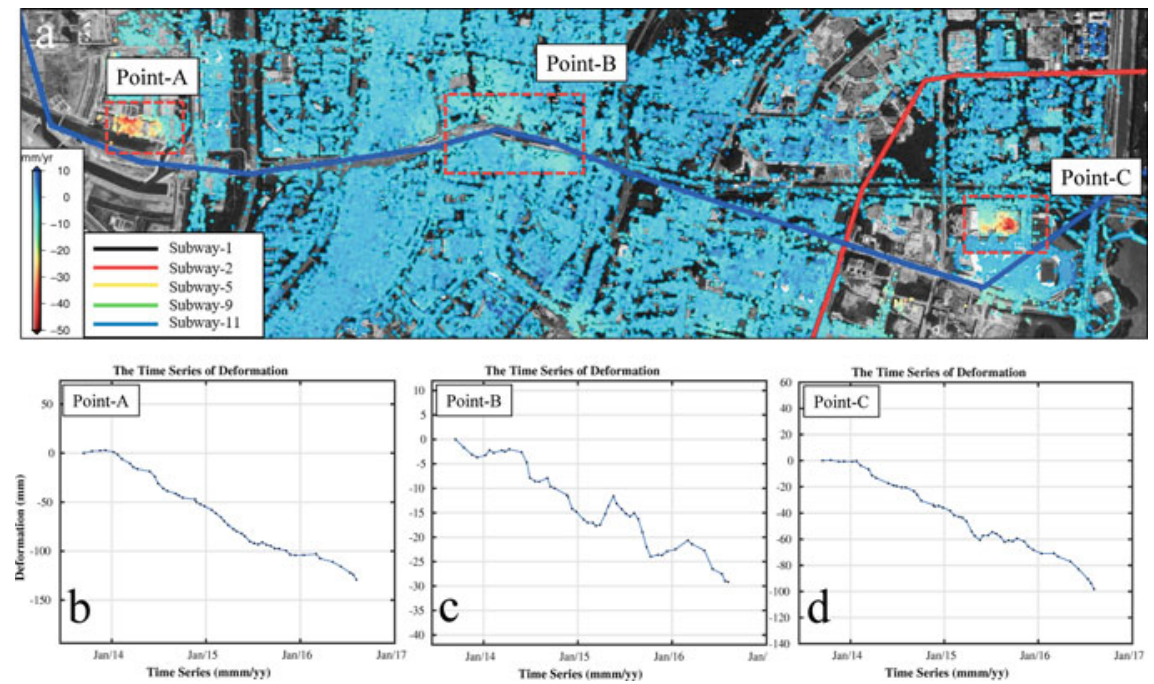

Fig. 21.9 a Deformation rate map along a metro line in Shenzhen from 50 TerraSAR-X images and MTInSAR processing; b Deformation time series of Point-A; $\mathbf{c}$ Deformation time series of Point-B; $\mathbf{d}$ Deformation time series of Point-C

In general, structural displacement observed with InSAR contains both thermal dilation and long-term deformation. Thermal dilation is caused by temperature variation of the measured structures (Crosetto et al. 2015; Qin et al. 2018). Figure 21.10 presents an example of the relationship between structural deformation and temperature for a high-rise building in Hong Kong. The thermal dilation coefficient of a structure depends on its materials.

Figure 21.11 shows two mean deformation velocity maps of road viaducts in Hong Kong, obtained by processing 29 TerraSAR-X images from 2013 to 2014. It can be seen that the deformation rates varied along the longitudinal direction of the roads. Figure 21.12 presents the deformation rate map of Stonecutter Bridge in Hong Kong after removing thermal expansion effects. The deformation rate map shows some clear deforming areas on the bridge deck.

Processing multiple SAR images from a single orbit provides information on the deformation along the line-of-sight only (Gernhardt and Bamler 2012; Schunert and Soergel 2012). By fusing multiple tracks of SAR data, infrastructures can be better observed and different deformation components, for example, the vertical and the horizontal components, can be resolved (e.g., Hu et al. 2014). 

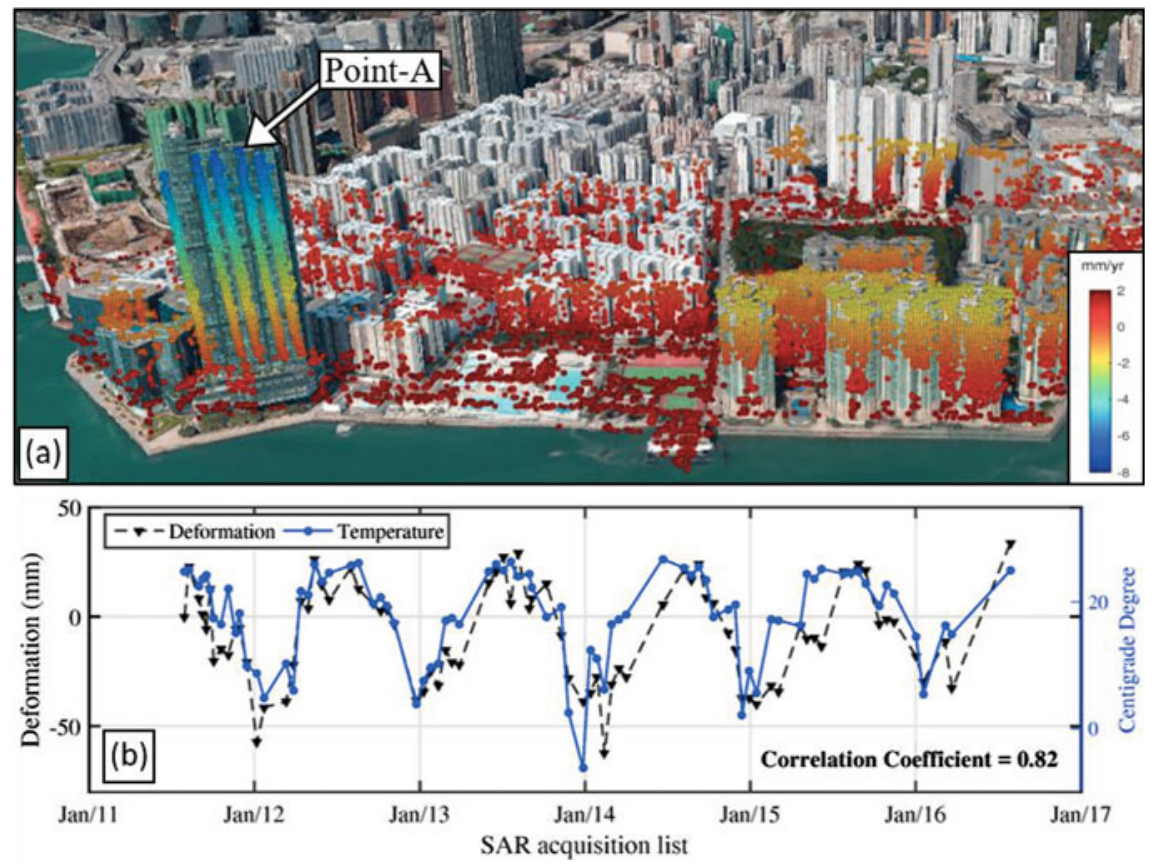

Fig. 21.10 a Geocoded deformation rate map of part of Kowloon Peninsula of Hong Kong from 80 COSMO-SkyMed images and MTInSAR processing. The map is superimposed on a Google Earth image (@ 2019 Google). b Deformation time series and temperature variations of Point-A
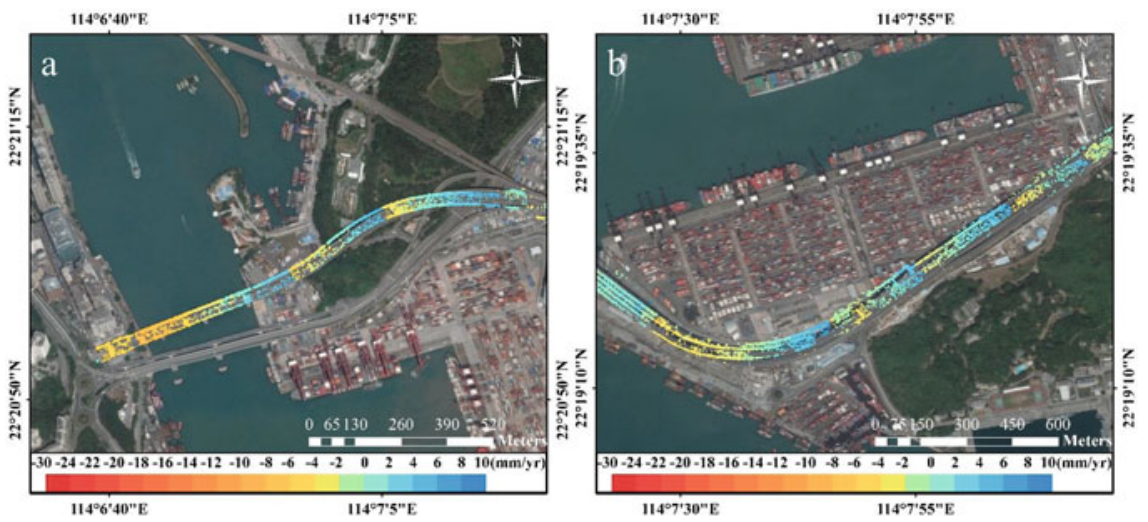

Fig. 21.11 Examples of road viaduct deformation in Hong Kong from 29 TerraSAR-X images and MTInSAR processing. a Tsing Kwai highway, b Tsing Sha highway 


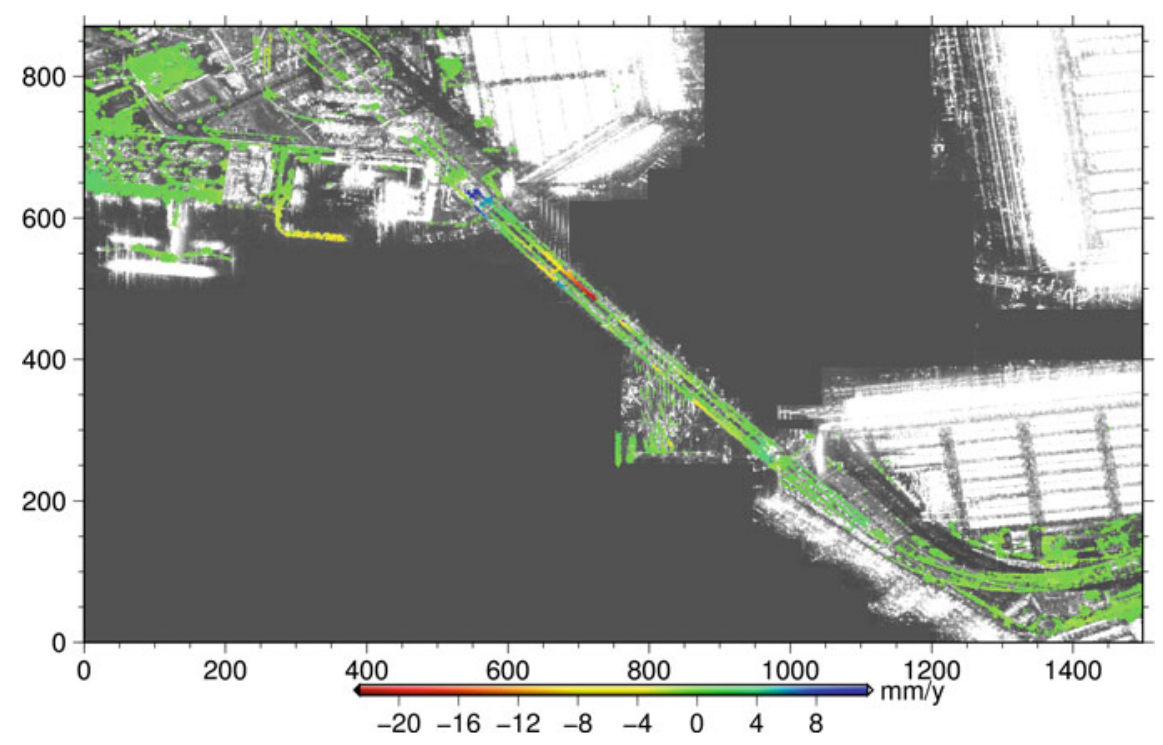

Fig. 21.12 Deformation rate map of Stonecutters Bridge in Hong Kong from 51 TerraSAR-X images and MTInSAR processing. The map was derived after removing the thermal dilation effect

\subsection{Summary}

We have reviewed the basic concepts of SAR, InSAR, and MTInSAR and their applications in urban environments. InSAR has benefited from the recent advances in spatial resolution and orbit control of spaceborne radar sensors and has become a vital technology in generating DEMs and in monitoring deformation phenomena related to, for example, ground subsidence and instability of infrastructures. InSAR techniques offer several advantages in such applications. For example, they can be applied in all weather conditions. This ability is especially useful in cloudy regions. Spaceborne InSAR technology can easily cover a large ground area with spatial and temporal resolutions hardly matched by any other technologies. InSAR however still has some shortcomings in these and other related applications. Further, research is still necessary to advance technology in terms of developing new SAR sensors, systems, and data processing algorithms. For example, geostationary satellite SAR constellations and P-band SAR sensor systems are currently being investigated. It can be expected that the capability of InSAR technology will be significantly enhanced in the near future. 


\section{References}

Adam N, Kampes B, Eineder M (2005) Development of a scientific permanent scatterer system: modifications for mixed ERS/ENVISAT time series. Envisat and ERS symposium

Berardino P, Fornaro G, Lanari R, Sansosti E (2002) A new algorithm for surface deformation monitoring based on small baseline differential SAR interferograms. IEEE Trans Geosci Remote Sens 40(11):2375-2383

Cao N, Lee H, Jung (2016) A phase-decomposition-based PSInSAR processing method. IEEE Trans Geosci Remote Sens 54(2):1074-1090

Costantini M (1998) A novel phase unwrapping method based on network programming. IEEE Trans Geosci Remote Sens 36(3):813-821

Crosetto M, Monserrat O, Cuevas-González M, Devanthéry N, Luzi G (2015) Measuring thermal expansion using X-band persistent scatterer interferometry. ISPRS J Photogr Remote Sens 100:84-91

Farr TG, Rosen PA, Caro E, Crippen R, Duren R, Hensley S, Kobrick M, Paller M, Rodriguez E, Roth L, Seal D, Shaffer S, Shimada J, Umland J, Werner M, Oskin M, Burbank D, Alsdorf D (2007) The Shuttle Radar Topography Mission. Rev Geophys 45(2)

Ferretti A, Fumagalli A, Novali PC, Rocca F, Rucci A (2011) A new algorithm for processing interferometric data-stacks: SqueeSAR. IEEE Trans Geosci Remote Sens 49(9):3460-3470

Ferretti A, Prati C, Rocca F (2001) Permanent scatterers in SAR interferometry. IEEE Trans Geosci Remote Sens 39(1):8-20

Fialko Y (2004) Evidence of fluid-filled upper crust from observations of postseismic deformation due to the 1992 Mw7.3 Landers earthquake. J Geophy Res Solid Earth 109(B8):B08401

Fornaro G, Verde S, Reale D, Pauciullo A (2015) CAESAR: an approach based on covariance matrix decomposition to improve multibaseline-multitemporal interferometric SAR processing. IEEE Trans Geosci Remote Sens 53(4):2050-2065

Gernhardt S, Bamler R (2012) Deformation monitoring of single buildings using meter-resolution SAR data in PSI. ISPRS J Photogr Remote Sens 73:68-79

Ghiglia DC, Romero LA (1994) Robust two-dimensional weighted and unweighted phase unwrapping that uses fast transforms and iterative methods. J Opt Soc Am A 11(1):107-117

Goldstein RM, Engelhardt H, Kamb B, Frolich RM (1993) Satellite radar interferometry for monitoring ice sheet motion: application to an Antarctic ice stream. Science 262:1525

Goldstein RM, Werner CL (1998) Radar interferogram filtering for geophysical applications. Geophys Res Lett 25(21):4035-4038

Goldstein RM, Zebker HA, Werner CL (1988) Satellite radar interferometry: two-dimensional phase unwrapping. Radio Sci 23(4):713-720

Hooper A, Segall P, Zebker H (2007) Persistent scatterer interferometric synthetic aperture radar for crustal deformation analysis, with application to Volcán Alcedo, Galápagos. J Geophys Res 112(B7):B07407

Hooper A, Zebker H, Segall P, Kampes B (2004) A new method for measuring deformation on volcanoes and other natural terrains using InSAR persistent scatterers. Geophys Res Lett 31(23):L23611

Hu H, Li ZW, Ding XL, Zhu JJ, Zhang L, Sun Q (2014) Resolving three-dimensional surface displacements from InSAR measurements: a review. Earth-Sci Rev 133:1-17

Jiang M, Ding X, Hanssen RF, Malhotra R, Ll C (2015) Fast statistically homogeneous pixel selection for covariance matrix estimation for multitemporal InSAR. IEEE Trans Geosci Remote Sens 53(3): 1213-1224

Jolivet R, Agram PS, Lin NY, Doin MP, Peltzer G, Li Z (2014) Improving InSAR geodesy using global atmospheric models. J Geophys Res Solid Earth 119(3):2324-2341 
Kampes BM (2006) Radar interferometry: persistent scatterer technique. Springer, Dordrecht

Kampes BM, Hanssen RF (2004) Ambiguity resolution for permanent scatterer interferometry. IEEE Trans Geosci Remote Sens 42(11):2446-2453

Lanari R, Mora O, Manunta M, Mallorqui JJ, Berardino P, Sansosti E (2004) A small-baseline approach for investigating deformations on full-resolution differential SAR interferograms. IEEE Trans Geosci Remote Sens 42(7):1377-1386

Liang H, Zhang L, Ding X, Lu Z, Li X (2019) Toward mitigating stratified tropospheric delays in multitemporal InSAR: a quadtree aided joint model. IEEE Trans Geosci Remote Sens 57(1):291303

Lombardini F (2005) Differential tomography: a new framework for SAR interferometry. IEEE Trans Geosci Remote Sens 43(1):37-44

Lu Z, Dzurisin D (2014) InSAR imaging of Aleutian volcanoes: monitoring a volcanic arc from space. Geophysical sciences. Springer-Verlag, Berlin Heidelberg

Lv X, Birsen Y, Mourad Z, Victoria B, Tarek A (2014) Joint-scatterer processing for time-series InSAR. IEEE Trans Geosci Remote Sens 52(11):7205-7221

Ma P, Lin H (2016) Robust detection of single and double persistent scatterers in urban built environments. IEEE Trans Geosci Remote Sens 54(4):2124-2139

Massonnet D, Feigl KL (1998) Radar interferometry and its application to changes in the Earth's surface. Rev Geophys 36(4):441-500

Mora O, Mallorqui JJ, Broquetas A (2003) Linear and nonlinear terrain deformation maps from a reduced set of interferometric SAR images. IEEE Trans Geosci Remote Sens 41(10):2243-2253

Perissin D, Rocca F (2006) High-accuracy urban DEM using permanent scatterers. IEEE Trans Geosci Remote Sens 44(11):3338-3347

Pritt MD, Shipman JS (1994) Least-squares two-dimensional phase unwrapping using FFT's. IEEE Trans Geosci Remote Sens 32(3):706-708

Qin X, Zhang L, Yang M, Luo H, Liao M, Ding X (2018) Mapping surface deformation and thermal dilation of arch bridges by structure-driven multi-temporal DInSAR analysis. Remote Sens Environ 216:71-90

Qu F, Lu Z, Zhang Q, Bawden GW, Kim JW, Zhao C, Qu W (2015) Mapping ground deformation over Houston-Galveston, Texas using multi-temporal InSAR. Remote Sens Environ 169:290-306

Rossi C, Gernhardt S (2013) Urban DEM generation, analysis and enhancements using TanDEM-X. ISPRS J Photogr Remote Sens 85:120-131

Schunert A, Soergel U (2012) Grouping of persistent scatterers in high-resolution SAR data of urban scenes. ISPRS J Photogr Remote Sens 73:80-88

Serrano-Juan A, Pujades E, Vázquez-Suñè E, Crosetto M, Cuevas-González M (2017) Leveling vs. InSAR in urban underground construction monitoring: Pros and cons. Case of La Sagrera railway station (Barcelona, Spain). Eng Geol 218:1-11

Shi G, Lin H, Ma P (2018) A hybrid method for stability monitoring in low-coherence urban regions using persistent and distributed scatterers. IEEE J Sel Top Appl Earth Obs Remote Sens 11(10):3811-3821

Sun Q, Zhang L, Ding X, Hu J, Li Z, Zhu J (2015) Slope deformation prior to Zhouqu, China landslide from InSAR time series analysis. Remote Sens Environ 156:45-57

Tadono T, Nagai H, Ishida H, Oda F, Naito S, Minakawa K, Iwamoto H (2016) Generation of the 30 M-Mesh Global Digital Surface Model by Alos Prism. ISPRS Int Arch Photogr Remote Sens Spatial Inf Sci XLI-B4:157-162

Wu S, Zhang L, Ding X, Perissin D (2018) Pixel-wise MTInSAR estimator for integration of coherent point selection and unwrapped phase vector recovery. IEEE Trans Geosci Remote Sens 57(5):2659-2668

Zebker HA, Rosen P (1994) On the derivation of coseismic displacement fields using differential radar interferometry: the Landers earthquake. In: Proceedings of IGARSS ‘94-1994 IEEE international geoscience and remote sensing symposium,vol 1, pp 286-288

Zhang L, Ding XL, Lu Z (2011a) Modeling PSInSAR time series without phase unwrapping. IEEE Trans Geosci Remote Sens 49(1):547-556 
Zhang L, Ding XL, Lu Z (2011b) Ground settlement monitoring based on temporarily coherent points between two SAR acquisitions. ISPRS J Photogr Remote Sens 66:146-152

Zhang L, Ding X, Lu Z, Jung HS, Hu J, Feng G (2014) A novel multitemporal InSAR model for joint estimation of deformation rates and orbital errors. IEEE Trans Geosci Remote Sens 52(6):3529-3540

Zhu XX, Bamler R (2010) Tomographic SAR inversion by L1-norm regularization: the compressive sensing approach. IEEE Trans Geosci Remote Sens 48(10):3839-3846

Zhu XX, Baier G, Lachaise M, Shi Y, Adam F, Bamler R (2018) Potential and limits of non-local means InSAR filtering for TanDEM-X high-resolution DEM generation. Remote Sens Environ 218:148-161

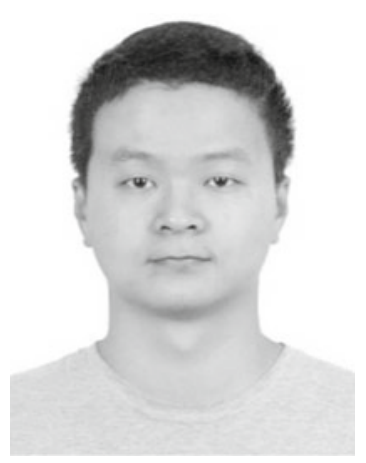

Hongyu Liang received a B.S. from Southwest Jiaotong University, Chengdu, China in 2013, and an M.Sc. in Geomatics from The Hong Kong Polytechnic University, Hong Kong, China, in 2014. He is currently working towards his Ph.D. in the Department of Land Surveying and Geo-Informatics, The Hong Kong Polytechnic University. His research interests include multitemporal InSAR modeling and parameter estimation, and largescale geohazard monitoring.

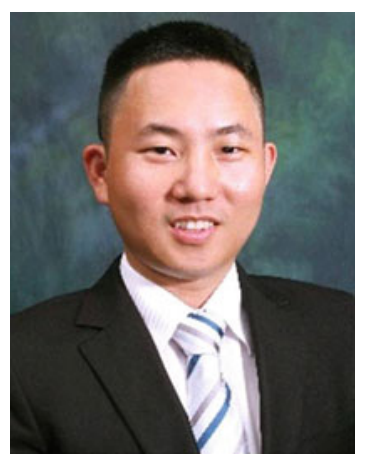

Wenbin Xu is Professor of Satellite Tectonic Geodesy at Central South University, Changsha, China. He is interested in studying and modeling earthquakes, volcanoes and tectonics. 

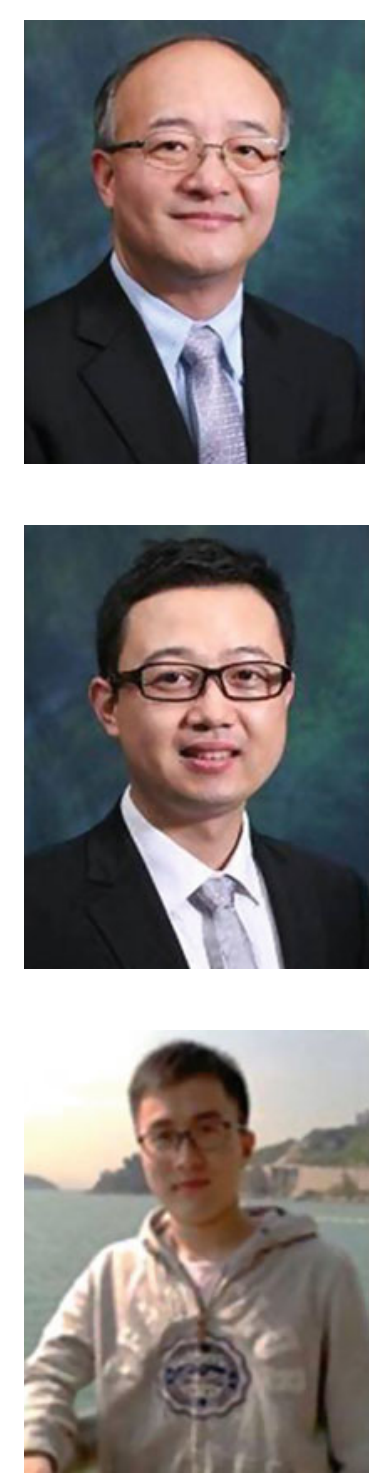

Xiaoli Ding is Chair Professor, the Department of Land Surveying and Geo-Informatics, The Hong Kong Polytechnic University. His research interests are in satellite positioning technologies (such as GPS), Synthetic Aperture Radar (SAR) and Interferometric Synthetic Aperture Radar (InSAR) technologies for ground deformation and structural health monitoring.

Lei Zhang is currently a Senior Research Fellow at The Hong Kong Polytechnic University. His research mainly focuses on developing advanced satellite radar data processing algorithms, and the application of interferometry technologies to image deformation associated with natural hazards and urban infrastructure instability.

Songbo Wu received a B.S. from Xinjiang University, Xinjiang, China in 2012, and an M.Sc. from South-West Jiaotong University, Sichuan, China in 2015. He is currently working towards his Ph.D. in the Department of Land Surveying and Geo-Informatics (LSGI), The Hong Kong Polytechnic University, Hong Kong. He is interested in InSAR modeling and the study of urban resilience using satellite remote sensing data. 
Open Access This chapter is licensed under the terms of the Creative Commons Attribution 4.0 International License (http://creativecommons.org/licenses/by/4.0/), which permits use, sharing, adaptation, distribution and reproduction in any medium or format, as long as you give appropriate credit to the original author(s) and the source, provide a link to the Creative Commons license and indicate if changes were made.

The images or other third party material in this chapter are included in the chapter's Creative Commons license, unless indicated otherwise in a credit line to the material. If material is not included in the chapter's Creative Commons license and your intended use is not permitted by statutory regulation or exceeds the permitted use, you will need to obtain permission directly from the copyright holder.

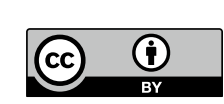

